\title{
Effect of Porosity on Compressive Strength of Resin Modified Glass lonomer Luting Cements
}

\author{
Al-Kadhim $\mathrm{AHA}^{1}$ and Abdullah $\mathrm{H}^{2}$ \\ ${ }^{1}$ Faculty of Dentistry, Islamic Science University of Malaysia \\ ${ }^{2}$ Faculty of Dentistry, University of Malaya.
}

\section{ABSTRACT}

Introduction: The purpose of this study was to decide on the relation between types of mixing and the porosity of diameter $(1-100) \mu \mathrm{m}$ and compressive strength of RMGIC. Methods: Fifteen specimens $6 \mathrm{~mm}$ height and $4 \mathrm{~mm}$ in diameter were prepared for each type of luting cement and were stored in distilled water at $37^{\circ}$ $C$ for 24 hours. The compressive strength was determined. The fractured surfaces of 10 randomly selected specimens of each cement type were analyzed using SEM at 250 times magnification, and five photomicrographs were taken at five random places. All the photomicrographs were analyzed using image analyzer software to determine the amount and size of porosity present. Results: There was no significant difference in compressive strength between different mixing methods, but it had a significant impact by increasing the percentage of porosity of diameter $(1-100) \mu \mathrm{m}$ in diameter of RMGIC. There was no linear relationship between compressive strength and porosity $(1-100) \mu \mathrm{m}$ in diameter for both types of luting cements $(P>0.05)$. Conclusion: No significant differences in compressive strength were found using different mixing methods. The size and number of porosity in the specimens of encapsulated cements were greater than those of hand-mixed cements. The porosity $(1-100) \mu \mathrm{m}$ in diameter and the compressive strength bore no linear relationship to each other.

KEYWORDS: Mechanical tests, resin modified glass ionomer cement, luting materials, porosity.

\section{INTRODUCTION}

The term "cement" implicatively insinuates the materials are going to be acclimated to lute or glue things together. Dental cements retain appliances and recuperations in situ with macromechanical and micromechanical retentions. Some dental cements are adhesive via chemical bonds, however, most are not. ${ }^{1,2}$ Luting agents comprise a broad class of materials that attach and seal dental restorations and prosthetic device to teeth. Early luting agents, with adhesive capability, are being introduced in an effort to improve clinical success. The choice of luting agents rely on the clinical situation combined

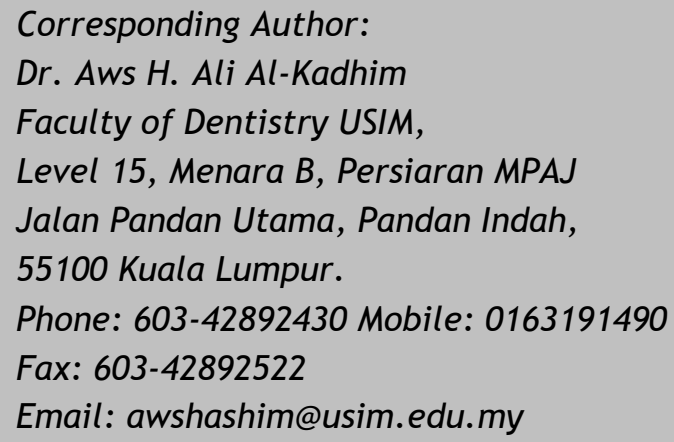

with the physical, biological, and handling properties of the luting agent. ${ }^{3,4,5}$ Caries and crown dislodgement are the common reasons for failure of crown and bridges. Caries may also relate to cement micro fracture and consequent micro leakage; the dislodgment may be related directly to gross mechanical failure of luting cements., ${ }^{3,5}$ The properties of luting materials generally are divided into mechanical properties which are evoked by the application of mechanical forces and physical properties that do not involve application of mechanical forces. ${ }^{6}$ In recent years, the most common water-based cements utilized for final cementation of crowns and bridges are glass ionomer cements. ${ }^{7}$ Various techniques have been used to understand the complex microstructure of glass ionomer cements, together with analysis, optical research, infrared spectrum analysis, microscopy (both transmission and SEM), and x-ray microanalysis. Each of those techniques has contributed to understanding the setting reaction, composition, and microstructure of glass ionomer cements. ${ }^{8}$ Although 
the conventional glass ionomer cements have some excellent features, their clinical usage is limited because they suffer from several disadvantages like short operating time, longer set time, delay setting, technique sensitivity, and brittleness.

In order to beat the preceding limitations of standard glass ionomer cements, nevertheless preserve the advantages, the idea of resin modified glass ionomer was developed. This resulted within the initial product, a light cure glass ionomer, being introduced in $1988 .^{6}$

Several workers have reported that mechanical properties of encapsulated materials were inferior or equivalent to those of the hand-mixed materials. It was recognized that mechanical mixing could end in the incorporation of air porousness within the cements, resulting in its weakening. ${ }^{9}$ The presence of pores or voids in sealing material cements could have an effect on the cements in a very range of adverse ways; notably wherever the lute is exposed to the oral cavity at the margins of cemented restorations, the presence of pores can increase the chances of mechanical failure. ${ }^{10,11}$ If the porousness in dental luting material cements is to be reduced, a stronger understanding of the character and origin of such voids is critical. In particular, information is needed regarding the amount, size and morphology of such pores, which can confirm the extent of their probable adverse effects. Moreover, information of the origin of such pores may be expedited by characterizing the pattern of voids.

Thus, the objectives of this study are to measure the percentage of porosity of diameter $(1-100) \mu \mathrm{m}$ at the fractured surface in Resin glass ionomer cements (hand-mixed and encapsulated); to determine the correlation between porosity of diameter $(1-100) \mu \mathrm{m}$ at the fractured surface and the compressive strength of luting cements.

\section{METHODS}

Two types of dental luting agents were utilized in this current research, which are hand-mixed resin glass ionomer luting cement namely, Fuji CEM (GC Corporation, Tokyo, Japan), and encapsulated conventional glass ionomer luting cement namely, Fuji plus CAPSULES (GC Corporation, Tokyo, Japan). Each type of luting agent consisted of fifteen specimens stored in distilled water for 24 hours at $37{ }^{\circ} \mathrm{C}$ with at least $90 \%$ relative humidity. All the materials were mixed according to the manufacturer's instructions. For the paste: paste resin modified glass ionomer cement, (Fuji CEM), an equal amount of paste was extruded from the pastepak cartridge loaded onto a dispenser as provided by the manufacturer and dispensed on a paper pad and mixed with a plastic spatula for 10 seconds as recommended. The encapsulated resin glass ionomer cement (Fuji plus CAPSULE) was mixed by rotating using RotoMix, (3M, EPSE, Seefeld, Germany) for 10 seconds without a centrifuge as recommended.

The following procedures were performed in a room at $23{ }^{\circ} \mathrm{C}$. The humidity was not controlled, but was around $50 \% \mathrm{RH}$. Specimens were prepared and the testing was conducted by a single person to maximize the standardization. Specimens of each material were prepared in a similar manner. Thirty test specimens were prepared in a cylindrical poly tetra fluroethylene split moulds, with internal dimensions $6 \mathrm{~mm} \pm 0.1 \mathrm{~mm}$ high and $4 \mathrm{~mm} \pm 0.1 \mathrm{~mm}$ diameter.

Within 60 seconds after the end of mixing, a slight excess of the mixed luting cement was placed into the mould, which was resting on a polyester strip in order to prevent the adhesion of poly-acrylic acid-based cements. For the encapsulated luting cements, the nozzle of the capsule was inserted into the cavity of the mould and touched to the wall of the mould. The nozzle was raised up slowly as the mould was filled.

One hundred and eighty seconds after the end of the mixing, the whole assembly of the specimens and mould were placed in an environmental chamber (incubator) at $37{ }^{\circ} \mathrm{C}$ and relative humidity of at least $90 \%$, for one hour. Exactly one hour after placing in the incubator the plates were removed and the end of the specimens were grinded flat at right angle to its long axis by using a 800 -grit silicon carbide paper under continuous water irrigation by using a Twin Wheel Grinder/Polisher machine (Buehler Uk, Conventry. England). The specimens were checked visually without magnification for air voids or chipped edges, all damaged specimens were discarded. And in order to facilitate the removal of the hardened cement specimens, the internal surfaces of the mould were evenly coated with paraffin wax. The luting cements specimens were 
carefully removed from the moulds and then stored in distilled water in an environmental chamber at $37^{\circ} \mathrm{C}$ for 23 hours.

\section{EVALUATION OF COMPRESSIVE STRENGTH}

The Universal testing machine used in this study was SHIMADZU (SHIMADZU Corporation, Kyoto, Japan). The diameter of the specimens was measured with a micrometer screw gauge (Kawasaki, Japan) accurate to $10 \mu \mathrm{m}$. The flat ends of the specimens were covered with a wet piece of filter paper to guarantee the specimens were tested "wet" and a compressive load applied, with a crosshead speed of $0.5 \mathrm{~mm} / \mathrm{min}$ to the long axis of the specimens. The maximum load to failure was recorded and the procedure repeated so that the minimum of 15 nominally identical standard cylindrical specimens had been fractured for each type of luting cement.

\section{POROSITY EVALUATION}

After the compressive strength assessment, the fractured surface of one fragment which was randomly chosen from ten randomly selected specimens for each group were examined by SEM (XL 40 series, PHILIPS, Holland). The specimens were sputter coated with gold prior to SEM examination and the fractured surfaces were observed at an operating voltage of $3 \mathrm{kV}$. Photomicrographs were taken by scanning electron microscope at X250 original magnification. SEM imaging was done on low vacuum mode. Five micrographs were taken for each fractured surface at random places in order to determine the percentage of porosity of diameter $(1-100) \mu \mathrm{m}$ at the fractured surfaces by using the Direct Counting Method as shown in Figures 1 and 2.

\section{Direct counting method}

Direct counting method was used in this study to measure the percentage of porosity at the fracture surface; this method has the advantages of being reliable and simple and showed no difference as compared with the Point counting method ${ }^{12,13}$. The disadvantage is that all the pores are assumed to be spherical in shape.

The direct counting method categorized the pores into four categories according to its diameter, which is $<1 \mu \mathrm{m},(1-10) \mu \mathrm{m},(10-50) \mu \mathrm{m},(50-100) \mu \mathrm{m}$, and because pores of diameter less than $1 \mu \mathrm{m}$ have no effect on the mechanical properties of luting cements $^{14}$, this category of pores was eliminated from this study.

All pores in different size ranges were identified and the longest pore diameter measured within photomicrographs with a digital micrometer (Image Analyzer Software, Leica QwinLite, Leica Microsystems imaging solution Ltd., Cambridge, UK). The percentage of porosity for each size range within a given measurement area $\left(\mathrm{N}_{\mathrm{A}}\right)$ was calculated by the following formula:

$$
P_{S}=\left(n r^{2} \pi / N_{A}\right) \times 100
$$

Where

$P_{s}$ - percentage of porosity for each size interval.

$\mathrm{n}$ - number of pores

$r$ - radius of pores.

$\mathrm{N}_{\mathrm{A}}$ - measurement area.

The diameter measurement of the pores for each photomicrograph was repeated twice by the same operator within 3 days interval between each reading, by using the image analyzer, the mean values were taken to measure the percentage of porosity by using the direct counting method.

\section{RESULTS}

\section{COMPRESSIVE STRENGTH}

The compressive strength for both luting cements that were used in this study were as shown in table 1:

Table 1: Compressive strength for both luting cements.

\begin{tabular}{lcll}
\hline $\begin{array}{l}\text { Luting } \\
\text { cement }\end{array}$ & $\mathrm{n}$ & $\begin{array}{l}\text { Compressive } \\
\text { strength } \\
\mathrm{MPa}\end{array}$ & $\begin{array}{l}\text { Standard } \\
\text { deviation }\end{array}$ \\
$\begin{array}{l}\text { Fuji CEM } \\
\text { Fuji plus }\end{array}$ & 15 & 103.8298 & 7.877 \\
\begin{tabular}{l} 
CAPSULE \\
\hline
\end{tabular} & 15 & 100.0231 & 14.616 \\
\hline
\end{tabular}

Because all the values were not normally distributed according to the bell curve, Mann-Whitney $U$ test was used to compare the compressive strength between groups, the level of significance was set as $\mathrm{P}<0.05$. It showed that there was no statistically significant difference $(P>0.05)$ between the compressive 
strength of Fuji CEM and Fuji plus CAPSULE as shown in table 2 .

Table 2: Mann-Whitney $U$ value as used to compare compressive strength between groups.

\begin{tabular}{lcc}
\hline \multicolumn{2}{c}{$\begin{array}{c}\text { Compressive strength } \\
\text { Median (IQR) }\end{array}$} & p value \\
\cline { 1 - 2 } Fuji CEM & Fuji plus CAPSULE & \\
\hline $101.777(15.1175)$ & $96.033(27.508)$ & 1 \\
\hline
\end{tabular}

\section{POROSITY}

The objective was to compare the percentages of porosity (1-100) $\mu \mathrm{m}$ in diameter between both types of luting cements. Porosity was categorized with respect to the diameter in three categories, porosity (1-10) $\mu \mathrm{m},(10-50) \mu \mathrm{m},(50-100) \mu \mathrm{m}$.

Percentage of porosity (1-10) $\mu \mathrm{m}$ mean and standard deviation of luting cements used in this study as shown in table 3.

Table 3: Percentage of porosity $(1-10) \mu \mathrm{m}$ mean and standard deviation of luting cements used in this study.

\begin{tabular}{cccc}
\hline $\begin{array}{c}\text { Luting } \\
\text { cement }\end{array}$ & $\mathrm{n}$ & $\begin{array}{c}\text { Percentage of porosity } \\
(1-10) \mu \mathrm{m} \text { [mean(\%)] }\end{array}$ & $\begin{array}{c}\text { Standard } \\
\text { deviation }\end{array}$ \\
\hline Fuji CEM & 10 & 0.049 & 0.0228 \\
\hline $\begin{array}{l}\text { Fuji plus } \\
\text { CAPSULE }\end{array}$ & 10 & 0.072 & 0.0286 \\
\hline
\end{tabular}

While the Percentage of porosity $(10-50) \mu m$ mean and standard deviation of luting cements used in this study were as in table 4.

Table 4: Percentage of porosity $(10-50) \mu m$ mean and standard deviation of luting cements.

\begin{tabular}{lccc}
\hline $\begin{array}{c}\text { Luting } \\
\text { cement }\end{array}$ & $\mathrm{n}$ & $\begin{array}{c}\text { Percentage of porosity } \\
(10-50) \mu \mathrm{m} \text { [mean(\%)] }\end{array}$ & $\begin{array}{c}\text { Standard } \\
\text { deviation }\end{array}$ \\
\hline Fuji CEM & 10 & 0.176 & 0.13566 \\
\hline $\begin{array}{l}\text { Fuji plus } \\
\text { CAPSULE }\end{array}$ & 10 & 2.422 & 0.67716 \\
\hline
\end{tabular}

And finally the Percentage of porosity (50-100) $\mu \mathrm{m}$ mean and standard of luting cements used in this study as shown in table 5 .
Table 5: Percentage of porosity $(50-100) \mu m$ mean and standard deviation of luting cements.

\begin{tabular}{lccc}
\hline $\begin{array}{c}\text { Luting } \\
\text { cement }\end{array}$ & $\mathrm{n}$ & $\begin{array}{c}\text { Percentage of porosity } \\
(50-100) \mu \mathrm{m} \text { [mean(\%)] }\end{array}$ & $\begin{array}{c}\text { Standard } \\
\text { deviation }\end{array}$ \\
\hline Fuji CEM & 10 & 0.291 & 0.73278 \\
\hline $\begin{array}{l}\text { Fuji plus } \\
\text { CAPSULE }\end{array}$ & 10 & 1.703 & 1.27570 \\
\hline
\end{tabular}

Mann-Whitney test was used to compare the percentage of porosity of diameter (1-10) $\mu \mathrm{m}$ between groups, the level of significance was set as $P<0.05$. It showed that the percentage of porosity $(1-10) \mu \mathrm{m}$ in diameter of Fuji plus CAPSULE was not statistically significant $(P>0.05)$ as compared with Fuji CEM as shown in table 6.

Table 6: Comparison of the percentage of porosity of diameter (1-10) $\mu \mathrm{m}$ between the luting cements.

\begin{tabular}{lcc}
\hline \multicolumn{2}{c}{ porosity $(1-10) \mu \mathrm{m}$ in diameter } \\
Median (IQR) & P value \\
\cline { 1 - 2 } Fuji CEM & Fuji plus CAPSULE & \\
\hline $0.0500(0.0425)$ & $0.0850(0.0600)$ & 0.0529 \\
\hline
\end{tabular}

While for the percentage of porosity of diameter (10-50) $\mu \mathrm{m}$ between groups, showed that the percentage of porosity (10-50) $\mu \mathrm{m}$ in diameter of Fuji CEM was highly significant $(P=0.001)$ as compared with that of Fuji Plus CAPSULE as shown in table 7.

Table 7: Comparison of the percentage of porosity of diameter (10-50) $\mu \mathrm{m}$ between the luting cements.

\begin{tabular}{lcc}
\hline \multicolumn{2}{c}{ porosity $(10-50) \mu \mathrm{m}$ in diameter } \\
Median (IQR) & p value \\
\hline Fuji CEM & Fuji plus CAPSULE & \\
\hline $0.14500(0.2375)$ & $2.3650(1.070)$ & 0.001 \\
\hline
\end{tabular}

On the other hand for the percentage of porosity $(50-100) \mu \mathrm{m}$, It showed the percentage of porosity (10-50) $\mu \mathrm{m}$ in diameter of Fuji CEM was highly significant $(P=0.001)$ as compared with that of Fuji Plus CAPSULE as shown in table 8. 
Table 8: Comparison of the percentage of porosity of diameter (50-100) $\mu \mathrm{m}$ between the luting cements.

\begin{tabular}{lcr}
\hline \multicolumn{2}{c}{ porosity $(50-100) \mu \mathrm{m}$ in diameter } \\
Median (IQR) & $\begin{array}{c}\mathrm{p} \\
\text { value }\end{array}$ \\
\hline Fuji CEM & Fuji plus CAPSULE & \\
\hline $0.0000(.2750)$ & $1.6350(1.1825)$ & 0.001 \\
\hline
\end{tabular}

Correlation between compressive strength and porosity

The objective was to determine if there is any correlation between the compressive strength and the incorporated porosity for each porosity category i.e. if there was any linear relationship between compressive strength and the percentage of porosity $(1-10) \mu \mathrm{m},(10-50) \mu \mathrm{m},(50-100) \mu \mathrm{m}$ in diameter. Spearman's Test was used to determine the relationship between the compressive strength and the percentage of surface area porosity at the
Table 9: Correlation between compressive strength and percentage of porosity of diameter $(1-10) \mu \mathrm{m}$

\begin{tabular}{lll}
\hline $\begin{array}{l}\text { Correlation between compressive strength and } \\
\text { percentage of porosity of diameter }(1-10)\end{array}$ & $\mu \mathrm{m}$ \\
\hline Group & $\mathrm{r}$ & P value \\
\hline Fuji CEM & 0.352 & 0.352 \\
\hline Fuji Plus CAPSULES & -0.191 & 0.596 \\
\hline
\end{tabular}

fracture surface for both types of resin modified glass ionomer cements as shown in table 9, table 10 and table 11. For Fuji CEM, there was no relationship between the compressive strength and porosity (1-10) $\mu \mathrm{m},(10-50) \mu \mathrm{m},(50-100) \mu \mathrm{m}$ in diameter. The $P$ values were $(P=0.310),(P=0.725), \quad(P=0.822)$ respectively. For Fuji Plus CAPSULE, there was no relationship between the compressive strength and porosity $(1-10) \mu \mathrm{m}, \quad(10-50) \mu \mathrm{m},(50-100) \mu \mathrm{m}$ in diameter. The $P$ values were $(P=0.596),(P=0.803)$, $(P=0.082)$.

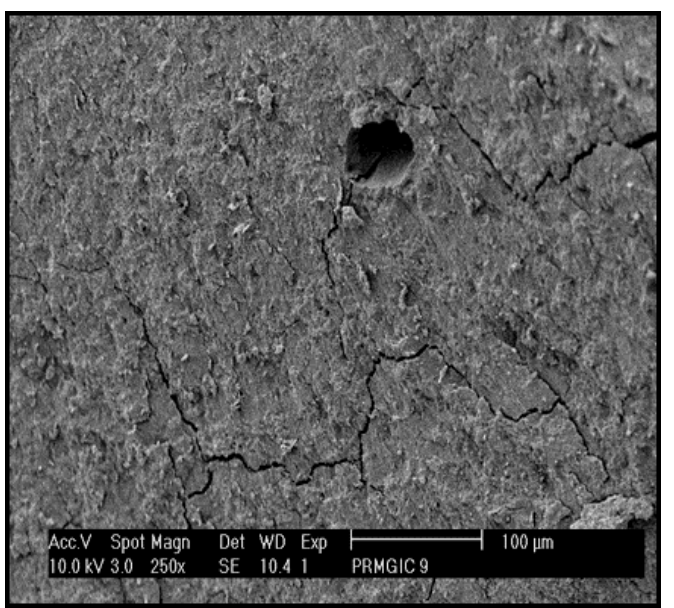

Figure 1: Scanning Electron Microscopy photo-micrographs showing the porosity at the fractured surface of Fuji CEM
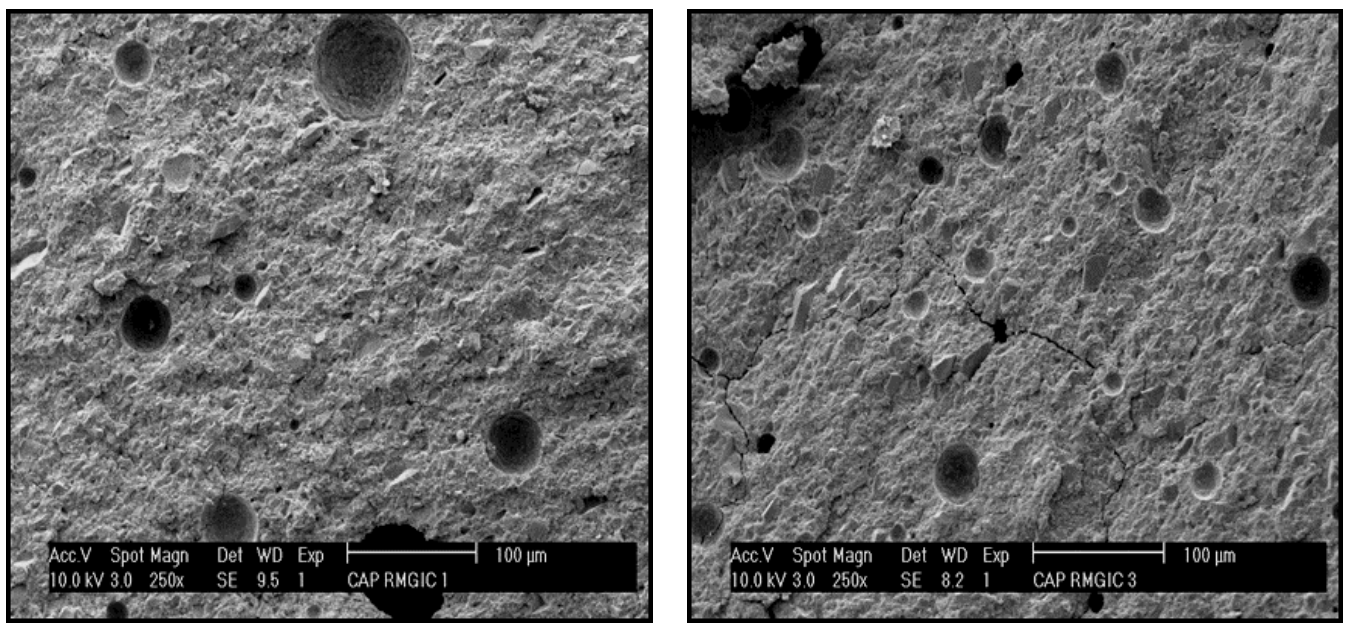

Figure 2: Scanning Electron Microscopy photo-micrographs showing the porosity at the fractured surface of Fuji plus CAPSULE. 
Table 10: correlation between compressive strength and percentage of porosity of diameter (10-50) $\mu \mathrm{m}$.

\begin{tabular}{ccc}
\hline \multicolumn{3}{c}{$\begin{array}{l}\text { Correlation between compressive strength and } \\
\text { percentage of porosity of diameter }(10-50) \mu \mathrm{m}\end{array}$} \\
\hline \multicolumn{1}{c}{ Group } & $\mathrm{r}$ & P value \\
\hline Fuji CEM & 0.358 & 0.310 \\
\hline Fuji Plus CAPSULES & -0.191 & 0.803 \\
\hline
\end{tabular}

Table 11: correlation between compressive strength and percentage of porosity of diameter (50-100) $\mu \mathrm{m}$.

\begin{tabular}{|c|c|c|}
\hline \multicolumn{3}{|c|}{$\begin{array}{l}\text { Correlation between compressive strength and } \\
\text { percentage of porosity of diameter }(50-100) \mu \mathrm{m}\end{array}$} \\
\hline Group & $r$ & P value \\
\hline Fuji CEM & 0.082 & 0.822 \\
\hline Fuji Plus CAPSULES & -0.576 & 0.082 \\
\hline
\end{tabular}

Spearman's rho Test.

$r=$ Correlation Coefficient.

Level of significance set at 0.05 .

\section{DISCUSSION}

The most common and useful mechanical properties for luting cement are compressive strength and flexural strength. ${ }^{5}$ Compressive strength has been considered as a critical indicator for the success of the luting cements because high compressive strength is necessary to tolerate the masticatory forces. ${ }^{1,11}$ In this present study, a Teflon Split mould which is capable of holding a maximum of seven samples were used to fabricate the specimen which were in accordance with the ISO IX 917:1991(E) for water based cements. This method appears to be sensitive to distinguishing changes in mechanical properties of brittle materials through changes in composition and level of porosity. ${ }^{15,16}$

The methods used in this present discipline to determine the compressive strength were similar to the previous studies, $9,15,19$ which was according to ISO 9917:1991 (E) for water-based cements. This method appears to be sensitive to distinguishing changes in mechanical properties of brittle materials through changing in composition and level of porosity. Pores acts as a source of stress concentration area, thus, making the specimen more brittle. ${ }^{18}$ In this study the measurement of porosity $(1-100) \mu \mathrm{m}$ at the fractured surfaces of ten randomly selected specimens, of each luting cements was carried out by using scanning electron microscopy. The photomicrographs of SEM were analyzed by using the image analyzer. In order to decrease the amount of bias in the results of the porosity decision on the fractured surface of each specimen, one fragment of the fractured specimens after the compressive strength test was chosen randomly and five photomicrographs of SEM were taken at five random different areas.

Nomoto and McCabe (2001) showed in their study that, compressive strength of hand-mixed glass ionomer cement is higher and statistically significant than that of encapsulated one. This study also showed that the compressive strength of hand -mixed resin modified glass ionomer cement (Fuji CEM) was higher than that of encapsulated glass ionomer cement (Fuji plus CAPSULE), but when the Kruskal Wallis test was used to compare the compressive strength, the $P$ value was more than 0.05 , thus there was no statistical difference between them. The standard deviation for the encapsulated resin modified glass ionomer cement was not lower than that of hand-mixed glass ionomer; this indicates that the encapsulated cement had no advantages in a term of reproducibility over hand-mixed materials. ${ }^{22}$ This study showed that small pores of diameter $(1-10)$ $\mu \mathrm{m}$ were present throughout the whole materials, and larger air bubbles $(50-100) \mu \mathrm{m}$ were less enormous and scattered intermittently. This result is in agreement with other studies. $8,9,16,23$

This present study showed that the encapsulated resin glass ionomer cement has more pores with diameter $(1-100) \mu \mathrm{m}$ than that of hand-mixed resin modified glass ionomer cement and was statically significant with $P$ value less than 0.05 . This could be related to the rapid mixing process of the mechanical mixing, which cause air inclusion, and slower mixing of hand-mixing procedure in which the material is spatulated helps to avoid these inclusions and may also collapse some air bubbles. ${ }^{9}$ This present study result is in agreement with other studies, ${ }^{9,16}$ where they found that more bubbles were produced during mechanical mixing. They also showed that there was a strong linear relationship between the mean of compressive strength and the mean of porousness in resin modified glass ionomer luting cement, and they claimed that the mixing method had minimal effect on the porosity and compressive strength of the this type of luting cement, and no mention of the diameter of pores was made that bore strong linear relationship with the compressive strength. ${ }^{9}$ 


\section{CONCLUSION}

Different mixing methods showed no significant difference in the compressive strength of resin modified glass ionomer cements. Encapsulated resin modified glass ionomer luting cements (Fuji plus CAPSULES) contained more air bubbles than the equivalent hand-mixed glass ionomer luting cement (Fuji CEM), Porosity of diameter (1-100) $\mu \mathrm{m}$ had no effect on the compressive strength.

\section{REFERENCES}

1. Piwowarczyk, A, and Lauer, H (2003). Mechanical properties of luting cements after water storage. Oper. Dent; 28 (5): 535-542.

2. Gladwin, $M$, and Bagby, $M$, (2000). Clincal Aspects of Dental Materials. Lippincott Williams and Wilkins.

3. Tuna, SH, Keyf, F (2006). Water Sorption and Solubility of Provisional and Permanent Luting Cements. Tur Dent J;30(3):19-24.

4. Attar, N, Tam, LE, and McComb, D. (2003). Mechanical and Physical properties of contemporary dental luting agents. J Prosthet Dent; 89(2):127-134.

5. Xie, D, Brantley, WA, Cullbertson, BM, and Wang, G. (2000). Mechanical properties and microstructure of glass ionomer cements. Dent mater; 16(2):129-138.

6. Dhuru, VB. (2004) Contemporary Dental Material. Manzar Khan, Oxford university press.

7. Craig, RG, and Powers, JM. (2002) Restorative dental materials. $11^{\text {th }}$ ed, Mosby-Elsevier Science Ltd.

8. Swift, EJ., and Dogan, AU, (1990). Analysis of glass ionomer cement with use of scanning electron microscopy. J prosthet Dent; 64 (2): 167-174.

9. Nomoto, R, Komoriyama, M, McCabe, JF, and Susumu $H$ (2004). Effect of mixing method on the porosity of encapsulated glass ionomer cement. J Dent; 20: 972-978.

10. Milutinović-Nikolić AD, Medić VB, and Vuković ZM. (2006). Porosity of different dental luting cements. Dent Mater; 23 (6): 674-678

11. White, SN, Yu, Z, Tom, JF, and Sangsurasak, S. (1994). In vivo microleakage of luting cements for cast crowns. J Prothet Dent; 71(4):333-338.

12. Denisova, LA, Maev, RG, Poyurovskaya, IY, Grineva, TV, Denisov, AF, Maeva EY, and Bakulin, EY. (2004). The use of acoustic microscopy to study the mechanical properties of glass-ionomer cement. Dent Mater; 20(4): 358-363.

13. Geirsson, J, Thomspon, JY, and Bayne, SC. (2004). Porosity evaluation and pore size determination of a novel directly placed ceramic restorative material. Dent mater; 20 (10): 987-995.

14. Bertenshaw, BW, and Piddock, V, (1993). Porosity in water-bases dental luting cements. J Material Science: material in medicine; 4:415417

15. Fleming, GJ, Farooq, AA, and Barralet, JE. (2003). Influence of powder/liquid ratio on performance of restorative glass-ionomer cement. Biomaterials; 24(23): 4173-4179.

16. Nomoto, R, and McCabe, JF. (2001). Effect of mixing methods on the compressive strength of glass ionomer cement. J Dent; 29:205-210.

17. Li, ZC, and White, SN. (1999). Mechanical properties of dental luting cements. J Prosthet Dent; 81(5):597-609.

18. McCabe, JF, and Ogden, AR. (1987). The relation between porosity compressive fatigue limit and wear in composite resin restorative materials. Dent Mater; 3: 9-12.

19. Wong, TC, and Bryant, RW. (1985). Glass ionomer cements: dispensing and strength. Aus Dent J; 30 (5): 336-340.

20. Crisp, S., Lewis, BG., Wilson, AD. (1976). Characterization of glass ionomer cements . Effect of powder: liquid ratio on physical properties. J Dent; 4(6): 287-290.

21. Billimgton, RW, Williams, JA, and Pearson, GJ. (1990). Variation in powder/ liquid ratio of restorative glass ionomer cement used in dental practice; Br Dent J; 169(6):164-167.

22. Williams, JA. and Belington, RW. (1991). Change in compressive strength of glass ionomer restorative materials with respect to time periods of $24 \mathrm{~h}$ to 4 months. J Oral Rehabil; 18:163-168.

23. Smales, R and Joyce, K, (1978) Finished surface texture, abrasion resistance, and porosity of Aspa glass-ionomer cement. J prosthet Dent; 40 (5): 549-553. 
